\title{
Nutraceutical value and safety of tomato fruits produced by mycorrhizal plants
}

\author{
M. Giovannetti ${ }^{1 *}$, L. Avio ${ }^{2}$, R. Barale ${ }^{3}$, N. Ceccarelli ${ }^{1}$, R. Cristofani ${ }^{4}$, A. Iezzi $^{1}$, F. Mignolli $^{1}$, \\ P. Picciarelli ${ }^{1}$, B. Pinto ${ }^{4}$, D. Reali ${ }^{4}$, C. Sbrana ${ }^{2}$ and R. Scarpato ${ }^{3}$ \\ ${ }^{1}$ Department of Crop Plant Biology, University of Pisa, Via del Borghetto 80, 56124 Pisa, Italy \\ ${ }^{2}$ CNR, Institute of Agricultural Biology and Biotechnology, UOS Pisa, Via del Borghetto 80, 56124 Pisa, Italy \\ ${ }^{3}$ Department of Biology, University of Pisa, Via Luca Ghini 5, 56126 Pisa, Italy \\ ${ }^{4}$ Department of Experimental Pathology, BMIE, University of Pisa, Via San Zeno 35/39, 56127 Pisa, Italy
}

(Received 26 January 2011 - Revised 26 April 2011 - Accepted 26 April 2011 - First published online 5 July 2011)

\section{Abstract}

Tomato fruit has assumed the status of 'functional food' due to the association between its consumption and a reduced likelihood of certain types of cancers and CVD. The nutraceutical value of tomatoes can be affected by the cultivation conditions, e.g. the phytochemical content of the fruits may increase with the establishment of beneficial mycorrhizal symbioses in the plants. A multidisciplinary study was carried out to gain knowledge on the antioxidant, oestrogenic/anti-oestrogenic and genotoxic activity of tomato fruits produced by mycorrhizal plants. The present results showed that the symbiosis positively affected the growth and mineral nutrient content of tomato plants and enhanced the nutritional and nutraceutical value of tomato fruits through modifications of plant secondary metabolism, which led to increased levels of lycopene in fruits obtained from mycorrhizal plants, compared with controls. Moreover, such changes did not result in the production of mutagenic compounds, since tomato extracts induced no in vitro genotoxic effects. Fruit extracts, both hydrophilic and the lipophilic fractions, originating from mycorrhizal plants strongly inhibited 17- $\beta$-oestradiol-human oestrogen receptor binding, showing significantly higher anti-oestrogenic power compared with controls. The present study shows that beneficial plant symbionts, such as mycorrhizal fungi, can lead to the production of safe and high-quality food, which is an important societal issue strongly demanded by both consumers and producers.

\section{Key words: Mycorrhizal tomatoes: Lycopene content: Tomato nutraceutical value}

Many epidemiological studies ${ }^{(1-3)}$ have reported that consumption of fruit and vegetables may play a role in the prevention of chronic diseases and in decreasing the risk of mortality from cancer and CVD. This protective action of plant-based food has been primarily attributed to secondary metabolites known as phytochemicals, which include polyphenolic products of the phenylpropanoid biosynthetic pathway. Polyphenols are widely distributed in plants, and are generally considered beneficial, as it has been documented that they can affect a number of processes in mammalian cells, suggesting an anti-carcinogenic and anti-atherogenic role ${ }^{(4)}$. However, some polyphenols and plant secondary metabolites, especially at higher concentrations, have proved to be genotoxic in various cell systems ${ }^{(5-7)}$.

Plant secondary metabolites can be constitutively expressed, but they can also be induced by a range of factors, including attack by fungal and bacterial pathogens and herbivores ${ }^{(8)}$. Recent investigations have shown that the plant secondary metabolic pathway is influenced by beneficial soil microorganisms - arbuscular mycorrhizal (AM) fungi (AMF) which establish mutualistic symbioses with the root systems of about $80 \%$ of land plant species, including the most important agricultural crops. AMF absorb and translocate soil mineral nutrients - mainly $\mathrm{P}, \mathrm{N}, \mathrm{S}, \mathrm{K}, \mathrm{Ca}, \mathrm{Fe}, \mathrm{Cu}$ and $\mathrm{Zn}$ - to host roots, enhance plant growth and biomass production in many crops, and positively affect crop tolerance of biotic and abiotic stresses ${ }^{(9)}$. In addition, AMF symbioses have been shown to modify terpenoid metabolism in species belonging to the Poaceae family ${ }^{(10)}$, increase the activity of several antioxidant enzymes in some shrubs ${ }^{(11)}$, increase total superoxide dismutase activity in bean roots ${ }^{(12)}$ and induce the non-mevalonate methylerythritol phosphate pathway

Abbreviations: ABTS, 2,2'-azino-bis-3-ethylbenzthiazoline-6-sulphonic acid; AM, arbuscular mycorrhizal; AMF, arbuscular mycorrhizal fungi; ASC, reduced ascorbate; DTT, dithiothreitol; DW, dry weight; $\mathrm{E}_{2}, 17-\beta$-oestradiol; GSH, reduced glutathione; GSSG, oxidised glutathione; HE, hydrophilic extract; LE, lipophilic extract; MN, micronucleus; YES, yeast oestrogen screen.

* Corresponding author: Professor M. Giovannetti, fax +39 050 2216641, email mgiova@agr.unipi.it 
of isoprenoid biosynthesis correlated with apocarotenoid accumulation $^{(13,14)}$. Although most of these data were obtained by analysing the roots of mycorrhizal plants, recent studies have reported that mycorrhizal symbioses increase phenolic content and antioxidant properties of artichoke leaves and flower heads in the field ${ }^{(15)}$ and enhance tomato fruit ascorbic acid content ${ }^{(16)}$.

Some isoflavones and other flavonoids, as well as lignans, coumestans and stilbenes, display oestrogenic (and antioestrogenic) activity, and are commonly referred to as phyto-oestrogens. Phyto-oestrogens, which do not necessarily show structural similarities to naturally occurring oestrogen $^{(17)}$, have been investigated for their putative preventive role in osteoporosis, menopausal symptoms, arteriosclerosis, heart disease and cancer ${ }^{(18,19)}$. They have a complex mode of action via interaction with the nuclear oestrogen receptor isoforms $\mathrm{ER} \alpha$ and $\mathrm{ER} \beta$, exhibiting either oestrogen-agonist or oestrogen-antagonist effects ${ }^{(20)}$. Interestingly, the levels of isoflavones with oestrogenic activity (e.g. of biochanin A, formononetin, genistein or daidzein) were impaired in some mycorrhizal plant species ${ }^{(21)}$.

Tomato fruits, extensively cultivated in Europe and throughout the world, have assumed the status of 'functional food', due to epidemiological evidence of reduced risk of certain types of cancers and $\mathrm{CVD}^{(22-25)}$. Tomato fruits are a reservoir of a range of antioxidant molecules, such as lycopene, ascorbic acid, vitamin E, carotenoids, flavonoids and phenolic compounds and, due to their high consumption rates, can provide a substantial part of the total intake of these beneficial nutraceutical molecules ${ }^{(26)}$. Among carotenoids, lycopene has been shown to have strong antioxidant activity and exhibits the highest physical quenching rate constant with singlet oxygen $^{(27)}$. In addition to these properties, lycopene has also been shown to induce cell-to-cell communications and modulate hormones, immune systems and other metabolic pathways $^{(28)}$.

In the present study, we developed a multidisciplinary approach to acquire knowledge on the nutraceutical value and safety of mycorrhizal tomato fruits produced by plants inoculated with the beneficial AM fungus Glomus intraradices and grown in the greenhouse (harvested at the ripening stage - full-red skin). Thus, we assessed, on inoculated and control plants, (1) the establishment of mycorrhizal colonisation, (2) plant growth parameters and nutrient uptake, (3) lycopene and main antioxidant content of raw tomato fruit extracts, (4) genotoxic activity in vitro of raw tomato fruit extracts and (5) oestrogenic/anti-oestrogenic activity of raw tomato fruit extracts.

\section{Materials and methods}

\section{Plant and fungal material and growth conditions}

Seeds of Solanum lycopersicum L., var. Money maker, were germinated in sterile moist quartz grit. After $8 \mathrm{~d}$ growth, plantlets were transferred to $100 \mathrm{ml}$ plastic pots (one plant/ pot) containing a mixture (1:1, by vol.) of soil and Terragreen (calcinated clay; OILDRI, Chicago, IL, USA), which was steam-sterilised $\left(121^{\circ} \mathrm{C}\right.$ for $\left.40 \mathrm{~min}\right)$ to kill naturally occurring AMF. The soil was a sandy loam collected near S. Piero (Pisa, Italy). Chemical and physical characteristics of the soil were as follows: pH (water) $8 \cdot 1$; clay, $4.9 \%$; silt, $6 \cdot 1 \%$; sand, $88.9 \%$; total $\mathrm{N}, 0.9 \mathrm{~g} / \mathrm{kg}$; available $\mathrm{P}\left(\mathrm{NaHCO}_{3}\right.$ soluble $\mathrm{P}$, Olsen analysis), $4 \cdot 15 \mathrm{mg} / \mathrm{kg}$; available $\mathrm{K}, 127 \mathrm{mg} / \mathrm{kg}$. In mycorrhizal treatments, each plant was inoculated with $30 \mathrm{~g}$ of the whole inoculum (mycorrhizal roots and soil containing spores and extraradical mycelium) of the AM fungal species G. intraradices Schenck \& Smith (isolate IMA6 from France, collector V. Gianinazzi-Pearson), obtained from Helianthus annuus L. pot cultures maintained in the collection of the Soil Microbiology Laboratory of the Department of Crop Plant Biology, University of Pisa, Italy. All pots received $50 \mathrm{ml}$ of a filtrate, obtained by sieving the mycorrhizal inoculum through a $50 \mu \mathrm{m}$ pore diameter sieve and a Whatman ${ }^{\circledR}$ paper no. 1 (Whatman International Ltd, Maidstone, Kent, UK), to ensure common microflora for all treatments. A total of thirteen control and thirteen mycorrhizal pots were set up. Plants were grown in a growth chamber, supplied with tap water as needed and with weekly fertilisation of half-strength Hoagland's solution ( $10 \mathrm{ml}$ per pot). After 1 month of growth, three pots per treatment were harvested and roots were observed after clearing and staining with 0.05\% Trypan blue in lactic acid ${ }^{(29)}$. Mycorrhizal root length was assessed by using the gridline intersect method ${ }^{(30)}$. Both mycorrhizal and control plants were transferred with their soil to 7 litre plastic pots containing a mixture of steam-sterilised soil and Terragreen. Plants were grown in a greenhouse for 4 months. Each pot was watered and fertilised by a timercontrolled drop irrigation system. Fertigation was applied to both treatments, using the nutrient solution with the following macronutrient composition: N, 6.0 mM; P, 0.1 mM; K, $3.9 \mathrm{~mm}$, dissolved in tap water. Rate and frequency of fertigation varied during the tomato growth cycle. For the first 2 weeks after the inoculation step, $20 \mathrm{ml}$ of the solution were manually added to the pots every third day. Thereupon, an automated drip irrigation device was utilised, and nutrients were dissolved in a 266 litre tank with well water. Frequency of solution delivery was increased throughout the experiment to compensate for the increased nutrient demand by plants. The solution in the tank was replaced every week.

The experiment was a completely randomised design with two inoculum treatments (inoculated plants and uninoculated control) and ten replicates.

\section{Plant growth and mycorrhizal colonisation}

Tomato fruits from control and mycorrhizal plants at the full-red stage were harvested from the first three trusses. Fully red ripe fruits with bright red colour and marketable appearance were selected. Fresh weight of fruits produced by each plant was recorded and DM (\%) was obtained by drying the fruit pieces in a thermo-ventilated oven at $70^{\circ} \mathrm{C}$ up to constant weight. The $\mathrm{pH}$ of tomato fruit was measured using a pH meter. Soluble solid concentration was measured with an optic refractometer (Model RL-3, Polskie Zaklady Optyczne, Warsaw, Poland) and expressed as ${ }^{\circ}$ Brix at $20^{\circ} \mathrm{C}$. 
Acidity was determined by titration with $0 \cdot 1 \mathrm{M}-\mathrm{NaOH}$ to reach $\mathrm{pH} 8 \cdot 1$ and expressed as $\mathrm{g}$ citric acid/100 $\mathrm{g}$ of fresh fruit weight. Shoot dry weight (DW) was determined after drying at $70^{\circ} \mathrm{C}$ in a thermo-ventilated oven for $3 \mathrm{~d}$. Host benefit was calculated for each fungal species as ((DW mycorrhizal plant DW non-mycorrhizal plant)/DW non-mycorrhizal plant) $\times 100$. Each plant root system was extracted from soil and both mycorrhizal and control roots were carefully washed with tap water, cut into $5 \mathrm{~cm}$ pieces, cleared and stained as described above. Percentage of AMF colonisation was assessed on each root sample by using the gridline intersect method. Colonised roots were mounted on microscope slides and observed under a Reichert-Jung (Wien, Austria) Polyvar light microscope to detect intraradical fungal structures.

\section{Mineral content of tomato fruits}

Fruit samples from control and mycorrhizal plants were oven dried for a week at $60^{\circ} \mathrm{C}$ and ground to powder with a mortar and pestle; $0 \cdot 1 \mathrm{~g}$ of each sample were then transferred into $25 \mathrm{ml}$ beakers. Concentrated nitric-perchloric acid solution (ratio 5:2) was added to each beaker and allowed to digest for $12 \mathrm{~h}$ at $120^{\circ} \mathrm{C}$ on a heating plate. The solution was transferred to $50 \mathrm{ml}$ volumetric flasks and double-distilled water was added. Fruit $\mathrm{C}$ and $\mathrm{N}$ were determined with a Finnigan Flash E1112 CHN-S elemental analyser (Thermo Fisher Scientific, Waltham, MA, USA), whereas $\mathrm{Ca}, \mathrm{Fe}, \mathrm{K}, \mathrm{Mg}, \mathrm{Mn}, \mathrm{Na}$, $\mathrm{P}$ and $\mathrm{Zn}$ analysis was performed with Optima 2000 OES DV ICP-OES (Perkin-Elmer, Waltham, MA, USA).

\section{Fruit sample preparation for activity assays}

A total of twenty-five fruits from each treatment were washed, cut into four pieces and seeds discarded. Fruit pieces were then pooled and stored at $-70^{\circ} \mathrm{C}$ until analyses. For biochemical analyses, the material was extracted by homogenising $1 \mathrm{~g}$ of frozen tomatoes in $10 \mathrm{ml}$ of $50 \mathrm{~mm}$-pottasium-phosphate buffer $(\mathrm{pH} 7 \cdot 5)$. The homogenate was then centrifuged for $15 \mathrm{~min}$ at $6000 \mathrm{~g}$ at $4^{\circ} \mathrm{C}$. Supernatants were collected and referred to as 'hydrophilic extract' (HE). The pellet was resuspended in $10 \mathrm{ml}$ of ethyl acetate, stirred for $15 \mathrm{~min}$ at $4^{\circ} \mathrm{C}$ and then centrifuged for $10 \mathrm{~min}$ at $6000 \mathrm{~g}$ at $4^{\circ} \mathrm{C}$, and the supernatant was collected. This procedure was performed twice. The organic phase was evaporated with a rotary evaporator, resuspended in $2 \mathrm{ml}$ of ethyl acetate and referred to as 'lipophilic extract' (LE).

\section{Biochemical analyses}

Analysis of lycopene. Lycopene content was determined according to the reduced volumes of organic solvents ${ }^{(31)}$. About $0.5 \mathrm{~g}$ of homogenised tomato were weighed, and combined with $5 \mathrm{ml}$ of acetone with $0.05 \%$ butylated hydroxytoluene, $5 \mathrm{ml}$ of ethanol and $10 \mathrm{ml}$ of hexane. The mixture was put on an orbital shaker for $15 \mathrm{~min}$. Water $(3 \mathrm{ml})$ was then added, before an additional $5 \mathrm{~min}$ on the shaker. Samples were then left in an upright position at room temperature for $5 \mathrm{~min}$ to allow for phase separation. Absorbance of the upper phase (hexane) was measured in a $1 \mathrm{~cm}$ path length quartz cuvette at $503 \mathrm{~nm}$, blanked with hexane.

Analysis of ascorbate. Total ascorbate, reduced ascorbate (ASC) and oxidised ascorbate were measured as reported ${ }^{(32)}$, with some modifications. The assay is based on the reduction of $\mathrm{Fe}^{3+}$ to $\mathrm{Fe}^{2+}$ by ascorbate and the spectrophotometric detection of $\mathrm{Fe}^{2+}$ complexed with 2,2'-dipyridyl. Oxidised ascorbate was reduced to ASC by pre-incubation of the sample with dithiothreitol (DTT). The excess of DTT was removed with $N$-ethylmaleimide, and total ascorbate was determined by the 2,2'-dipyridyl method. Oxidised ascorbate concentration was estimated from the difference between total ascorbate and ASC (without pre-treatment with DTT). Frozen tomato slurry ( $1 \mathrm{~g}$ ) from control and mycorrhizal plants was ground in a prechilled mortar with $0.8 \mathrm{ml}$ TCA $(6 \%, \mathrm{w} / \mathrm{v})$. The mixture was homogenised and then allowed to stand for several minutes. The homogenates were transferred to $2 \mathrm{ml}$ tubes and adjusted to a volume of $2 \mathrm{ml}$ with $6 \%$ TCA, and subsequently centrifuged for $5 \mathrm{~min}$ at $14000 \mathrm{~g}$. Total ascorbate was measured in a $2.0 \mathrm{ml}$ reaction mixture containing $0 \cdot 1 \mathrm{ml}$ aliquot of the supernatant, $0.2 \mathrm{ml}$ of $200 \mathrm{~mm}$-phosphate buffer ( $\mathrm{pH} 7.5)$ and $0.1 \mathrm{ml}$ of $10 \mathrm{mm-DTT}$. After incubation for $20 \mathrm{~min}$ at $42^{\circ} \mathrm{C}, 0.1 \mathrm{ml}$ of $0.5 \% \mathrm{~N}$-ethylmaleimide were added. ASC was determined in the same reaction mixture, except that $0.3 \mathrm{ml}$ of $200 \mathrm{~mm}$-phosphate buffer $(\mathrm{pH} \mathrm{7.5)}$ and $0.1 \mathrm{ml}$ water were added instead of DTT and $N$-ethylmaleimide. Colour was developed in the reaction mixture after addition of the following reagents: $0.5 \mathrm{ml}$ of $10 \%$ TCA, $0.4 \mathrm{ml}$ of $42 \%$ orthophosphoric acid, $0.4 \mathrm{ml}$ of $4 \% 2,2^{\prime}$-dipyridyl dissolved in $70 \%(\mathrm{v} / \mathrm{v})$ ethanol and $3 \%(\mathrm{w} / \mathrm{v}) \mathrm{FeCl}_{3}$. After mixing, the mixture was incubated at $42^{\circ} \mathrm{C}$ for $40 \mathrm{~min}$ and absorbance of $\alpha, \alpha^{\prime}$-bipyridyl complexed with reduced ferric iron was read at $525 \mathrm{~nm}$ using a UV-1204 spectrophotometer (Shimadzu Scientific Instruments, Columbia, MD, USA). A standard curve in the range $0-200 \mu \mathrm{g} / \mathrm{ml}$ of ASC was prepared.

Analysis of glutathione. Total, reduced (GSH) and oxidised (GSSG) glutathione content were determined with an enzymatic-recycling assay based on glutathione reductase ${ }^{(33)}$ with minor modifications. Frozen tomato slurry $(0.5 \mathrm{~g})$ from control and mycorrhizal plants were added to a chilled solution of $6 \% \mathrm{~m}$-phosphoric acid and $1 \mathrm{~mm}$-EDTA- $\mathrm{K}_{2}$ and transferred into $2 \mathrm{ml}$ tubes. Tubes were centrifuged at $20000 \boldsymbol{g}$ for $15 \mathrm{~min}$ at $4^{\circ} \mathrm{C}$. The supernatant was collected and used for analysis. Then, $0 \cdot 1 \mathrm{ml}$ of the supernatant were used for the assay of total glutathione (GSH + GSSG). Another $0 \cdot 1 \mathrm{ml}$ of the aliquot were first neutralised by adding $5 \mu$ l of triethanolamine and subsequently derivatised with $4 \mu \mathrm{l}$ of 2 -vinylpyridine to mask GSH. The tube was mixed until an emulsion was formed and incubated for $60 \mathrm{~min}$ at room temperature. This sample was used for the GSSG assay. GSH was estimated as the difference between total glutathione and GSSG. Glutathione content was measured in $1.2 \mathrm{ml}$ of the reaction mixture containing $0.3 \mathrm{ml}$ of $5 \% \mathrm{~K}_{2} \mathrm{HPO}_{4} \cdot 3 \mathrm{H}_{2} \mathrm{O}, 0.4 \mathrm{ml}$ of reagent 1 (150 mM-phosphate buffer, $15 \mathrm{mm-EDTA,} 0.3 \mathrm{~mm}-$ 5,5'-dithiobis-2-nitrobenzoic acid and 0.04\% bovine serum albumin), $0.32 \mathrm{ml}$ reagent 2 (1 mm-EDTA, $50 \mathrm{mm-imidazole}$ solution, $0.02 \%$ bovine serum albumin and $25.05 \mathrm{nkat} / \mathrm{ml}$ of glutathione reductase) and $0 \cdot 1 \mathrm{ml}$ of the sample. The reaction 
was started by the addition of $0.08 \mathrm{ml}$ of $9 \mathrm{~mm}-\mathrm{NADPH}$. The reaction was allowed to proceed for $2 \mathrm{~min}$ at room temperature and then immediately stopped by dipping tubes in boiling water for few seconds. A standard GSH curve in the range of $0-30 \mu \mathrm{g} / \mathrm{ml}$ was prepared.

Total phenolic compounds. Total soluble phenolics were extracted from frozen tomato slurry with $70 \%$ methanol, determined using Folin-Ciocalteu reagent, and expressed as quercetin equivalents ${ }^{(34)}$. The reaction mixtures included $0.125 \mathrm{ml}$ methanol extract, $0.5 \mathrm{ml}$ distilled water, $0.125 \mathrm{ml}$ Folin-Ciocalteu reagent, $1.25 \mathrm{ml}$ of $7 \%$ sodium carbonate and $1 \mathrm{ml}$ water. Absorbance was read at $760 \mathrm{~nm}$ after $90 \mathrm{~min}$ of incubation at room temperature. A standard curve for quercetin in the range of $0-50 \mu \mathrm{g} / \mathrm{ml}$ was prepared.

Total antioxidant activity. Antioxidant activity was measured using a method previously described ${ }^{(35)}$, with some modifications. The assay is based on the capacity of different antioxidant components to scavenge the 2,2'-azino-bis-3ethylbenzthiazoline-6-sulphonic acid (ABTS) radical cation $\left(\mathrm{ABTS}^{*+}\right.$ ) compared with a standard antioxidant (Trolox; Sigma Aldrich). ABTS $^{+}$was generated by mixing $2.45 \mathrm{~mm}$-potassium persulfate with $7 \mathrm{~mm}$-ABTS, which was then allowed to react in the dark at room temperature for $12-16 \mathrm{~h}$. For analysis of $\mathrm{HE}$ and LE antioxidant capacity, $110 \mu \mathrm{l}$ of the ABTS ${ }^{+}$ solution were diluted with $6 \mathrm{~mm}$-pottasium-phosphate buffer or $10 \mathrm{ml}$ ethanol, respectively, in order to obtain an absorbance of $0.70 \pm 0.02$ at $734 \mathrm{~nm}$. Then, $5,10,15 \mu \mathrm{l}$ of HE or LE were added to $1 \mathrm{ml}$ of the $\mathrm{ABTS}^{*+}$ solution. The decrease in absorbance was determined at $734 \mathrm{~nm} 15 \mathrm{~min}$ after initial mixing and every $15 \mathrm{~min}$ until the reaction reached a plateau (after $1 \mathrm{~h}$ ). Absorbance was determined as the difference between the $A_{734 \mathrm{~nm}}$ value before and after the addition of the sample (after $1 \mathrm{~h}$ ). Antioxidant activity is expressed as Trolox equivalents/fresh weight (mm/g fresh weight).

\section{Determination of genotoxic activity: in vitro mutagenicity assay}

Ames test. The mutagenicity Ames test is based on the ability of histidine-dependent mutated (his - ) bacterial strains to revert to the wild-type phenotype $($ his + ) when allowed to grow on agar plates containing minimal medium without histidine. The assay was performed on TA98 and TA100 tester strains of $S$. typhimurium, in the presence and absence of metabolic activation (S-9 mix) as described ${ }^{(36)}$. Using a semi-log scale, LE and HE were tested from 0.03 to $2.625 \mathrm{mg} /$ plate and from 0.04 to $25 \mathrm{mg} /$ plate, respectively. 2 -Aminofluorene was used as a positive control at $1 \mu \mathrm{g} /$ plate to check for functioning of both cell and S-9 mix. Negative controls were also set up, according to the solvent used to prepare each extract. For each experimental point, three independent plates per strain in the presence and absence of S-9 mix were set up.

Micronucleus assay. The analysis of micronucleus (MN) formation in phytohaemagglutinin-stimulated and cytochalasin B-blocked human peripheral lymphocytes, which detects chromosome breakage and/or malsegregation, is commonly used as a marker of genome damage ${ }^{(37)}$. Heparinised peripheral blood samples were obtained from three healthy, young, non-smoking male donors. After adding $0.3 \mathrm{ml}$ of the whole blood to $4.7 \mathrm{ml}$ of Roswell Park Memorial Institute (RPMI)-1640 (Invitrogen, Milano, Italy) supplemented with $20 \%$ fetal bovine serum (Invitrogen), $1.5 \%$ phytohaemagglutinin (Invitrogen) and $1.0 \%$ penicillin/streptomycin (Invitrogen), stimulated lymphocytes were incubated and cultured at $37^{\circ} \mathrm{C}$ for $72 \mathrm{~h}$. Using a semi-log scale, tomato extracts were assayed in the final concentration range of $0.0024-1.5$ and $0 \cdot 016-10 \mathrm{mg} / \mathrm{ml}$ for $\mathrm{LE}$ and $\mathrm{HE}$, respectively. Bleomycin (Sanofi-aventis, Milano, Italy) was used as a positive control. Negative controls were also set up, according to the solvent used to prepare each extract. Cytochalasin B $(6 \mu \mathrm{g} / \mathrm{ml}$; Sigma-Aldrich, Milano, Italy) was added at $44 \mathrm{~h}$ to all culture tubes to block cell cytokinesis. As described in detail elsewhere ${ }^{(38)}$, lymphocytes were harvested at the end of cell culturing by $4 \mathrm{~min}$ centrifugation at 2400 rotations $/ \mathrm{min}$, treated with $10 \mathrm{ml}$ of $0.075 \mathrm{~mm}-\mathrm{KCl}$ for a few minutes to lyse erythrocytes, prefixed in methanol-acetic acid (3:5), fixed in 100\% methanol, washed twice in methanol-acetic acid (5:1) and dropped onto clean glass slides. The air-dried slides were then stained in 5\% Giemsa. For each experimental point, 2000 bi-nucleated cells (1000 cells from replicate cultures) were scored for the presence of MN. MN frequency is expressed as the number of micronucleated bi-nucleates per 1000 bi-nucleated scored cells. Toxicity and/or cell cycle delay is expressed as cell proliferation index, which was calculated according to the following formula: $(\mathrm{M}+2 \mathrm{~B}+3 \mathrm{P}) /(\mathrm{M}+\mathrm{B}+\mathrm{P})$, where $\mathrm{M}$ (mononucleated), B (bi-nucleated) and $\mathrm{P}$ (plurinucleated) are the number of cells that have not yet entered the first mitosis $(\mathrm{M})$, and cells that have divided once (B) and twice (P, comprising both tri- and tetranucleated), respectively. $\mathrm{M}+\mathrm{B}+\mathrm{P}$ represents a total of at least 1000 cells scored.

\section{Determination of oestrogenic/anti-oestrogenic activities: the yeast oestrogen screen assay}

Oestrogenic/anti-oestrogenic activity of tomato samples was assessed using the Saccharomyces cerevisiae yeast strain RMY326 containing the human oestrogen receptor $\alpha$ and a Xenopus laevis vitellogenin ERE sequence linked to a lac $Z$ reporter gene encoding for the enzyme $\beta$-galactosidase ${ }^{(39)}$ Induction of reporter gene transcription by the complex receptor-ligand was detected and quantified by spectrophotometry (ULTROSPEC ${ }^{\circledR} 2100$ pro; Amersham Pharmacia Biotech, Cologno Monzese, Italy). The yeast oestrogen screen (YES) assay was described previously ${ }^{(40,41)}$. Determination of oestrogenic and anti-oestrogenic activity was conducted on both LE and HE. The extracts were tested in the range $0 \cdot 001-2 \cdot 0 \mathrm{mg} / \mathrm{ml}$. To test for oestrogenic activity, yeast cultures were incubated overnight in the presence of $10 \mathrm{~nm}-17-\beta$ oestradiol $\left(\mathrm{E}_{2}\right)$ as a positive control, vehicle (negative control), and increasing concentrations of tomato extracts alone. The enzymatic reaction was started by adding $O$-nitrophenyl $\beta$-D-galactopyranoside (Sigma-Aldrich) and incubating at $30^{\circ} \mathrm{C}$ for 5-10 min. The reaction was stopped by adding $\mathrm{Na}_{2} \mathrm{CO}_{3}$ and absorbance was measured at $420 \mathrm{~nm}$. $\beta$-Galactosidase activity was normalised to the number of cells assayed 
(optical density at $600 \mathrm{~nm}$ ). The amount of $\beta$-galactosidase is correlated with the potential oestrogenic activity of the sample and can be quantified by means of a logistic doseresponse curve generated with $\mathrm{E}_{2}$ (GraphPad 4.0; GraphPad Software Inc., San Diego, CA, USA). Oestrogenic (agonistic) activity of samples is expressed as a percentage of $\beta$-galactosidase activity obtained with $10 \mathrm{~nm}-\mathrm{E}_{2}$ (positive control). For anti-oestrogenic activity, yeast cells were co-treated overnight with $1 \mathrm{~nm}-\mathrm{E}_{2}$. Samples that successfully inhibited the activity of the natural ligand $\mathrm{E}_{2}$ led to a dose-dependent decrease in $\beta$-galactosidase expression, which was associated with a concurrent decrease in the rate of change in colour of the medium. A yeast culture containing $1 \mathrm{~nm}-\mathrm{E}_{2}$ alone was used as a positive control. Antagonistic activity, defined as ability of the extracts to antagonise the binding of the natural hormone to its receptor, is expressed as inhibition (\%) of $1 \mathrm{~nm}-\mathrm{E}_{2}$ activity by each sample. The drug 4-hydroxy tamoxifen (Sigma-Aldrich), which acts as an $\mathrm{E}_{2}$-antagonist in yeast ${ }^{(39,42)}$, was used as the control for antagonistic activity.

Lycopene, one of the most representative constituents of tomato fruits, accounting for more than $80 \%$ of total tomato carotenoids $^{(43)}$, was also tested in order to evaluate assay sensitivity in detecting the endocrine disrupting activity of this compound. Lycopene (L9879 Sigma-Aldrich) was tested from $10^{-9}$ to $10^{-4} \mathrm{M}$. $\mathrm{E}_{2}$, 4-hydroxy tamoxifen, lycopene and samples were dissolved in dimethyl sulfoxide (dimethyl sulfoxide-water $1: 1, \mathrm{v} / \mathrm{v}$ for the HE) and added to the yeast culture so that solvent concentration did not exceed $2 \%$ $(\mathrm{v} / \mathrm{v})$. The results are the mean of three independent experiments and standard deviations.

\section{Statistical analysis}

ANOVA of plant growth and mycorrhizal colonisation data were performed on SPSS 11.0 software (SPSS, Inc., Chicago, IL, USA), after the necessary transformations, and differences between means were determined by the appropriate test. The Tukey B procedure was used for comparing means. Percentage colonisation data were arcsine-transformed before analysis. Results from the Ames test are expressed as the mean number of revertants per plate, and evaluation of statistical significance was obtained by linear regression analysis calculated on the dose-response curve. MN frequencies and cell proliferation index values were processed by the Dunnett test, which performs a multiple comparative calculation of treated $v$. control cultures. Oestrogenic/anti-oestrogenic activity was evaluated by ANOVA first-order regression analysis, (PROC GLM of SAS, version 8.2; SAS Institute Inc., Cary, NC, USA) and each activity was considered significant when it reached at least a $20 \%$ increase compared with the control (agonistic activity) or a $40 \%$ decrease (antagonistic activity).

\section{Results}

\section{Mycorrhizal colonisation}

At harvest, G. intraradices successfully established mycorrhizal symbioses with tomato plants, showing percentages of
Table 1. Mineral element concentrations in control and mycorrhizal tomato fruits

(Mean values with their standard errors of three replicates)

\begin{tabular}{|c|c|c|c|c|c|}
\hline & \multicolumn{2}{|c|}{$\begin{array}{c}\text { Control } \\
\text { (mg/kg DW) }\end{array}$} & \multicolumn{2}{|c|}{$\begin{array}{l}\text { Mycorrhizal } \\
\text { (mg/kg DW) }\end{array}$} & \multirow[b]{2}{*}{$P$} \\
\hline & Mean & SE & Mean & SE & \\
\hline $\mathrm{C}+$ & 44.66 & 0.17 & 44.56 & 0.22 & NS \\
\hline $\mathrm{N} \dagger$ & $2 \cdot 26$ & 0.02 & 2.25 & 0.08 & NS \\
\hline $\mathrm{Ca}$ & $1456 \cdot 0$ & 14.0 & 1674.0 & 4.0 & $* \star \star$ \\
\hline $\mathrm{Fe}$ & $57 \cdot 21$ & 1.55 & 56.67 & 4.03 & NS \\
\hline $\mathrm{K}$ & $25970 \cdot 0$ & 490.0 & $28870 \cdot 0$ & 295 & ** \\
\hline $\mathrm{Mg}$ & $1000 \cdot 0$ & $7 \cdot 0$ & $1005 \cdot 0$ & $6 \cdot 0$ & NS \\
\hline $\mathrm{Mn}$ & 7.99 & 0.11 & $7 \cdot 88$ & 0.09 & NS \\
\hline $\mathrm{Na}$ & 383.60 & 19.50 & 397.90 & 22.4 & NS \\
\hline $\mathrm{P}$ & $1525 \cdot 0$ & $5 \cdot 0$ & $2432 \cdot 0$ & 33.0 & $\star \star * *$ \\
\hline $\mathrm{Zn}$ & $12 \cdot 61$ & 0.59 & 16.09 & 0.35 & ** \\
\hline
\end{tabular}

DW, dry weight.

Mean values were significantly different: ${ }^{\star \star} P \leq 0.01$ and ${ }^{\star \star *} P \leq 0.001$ (two-tailed paired $t$ test).

$\dagger \mathrm{C}$ and $\mathrm{N}$ are expressed in $\mathrm{g} / 100 \mathrm{~g} \mathrm{DW}$

colonised root length ranging from 40 to $70 \%$. No colonisation was observed in uninoculated plants.

\section{Plant biomass, mineral content and quality parameters}

Shoot biomass production was significantly affected by mycorrhizal symbiosis $(P=0.001)$ : host benefit was 18.3 (SE 3.2$) \%$, based on total shoot weights. Fruit $\mathrm{Ca}, \mathrm{K}, \mathrm{P}$ and $\mathrm{Zn}$ concentrations were higher in mycorrhizal plants than that of control plants. Fruit concentrations of all other elements were unaffected by AM fungal colonisation (Table 1). Fruit quality parameters of mycorrhizal and control tomatoes are shown in Table 2. Fruit DM, pH, soluble solids and acidity were not significantly affected by mycorrhizal colonisation.

\section{Lycopene and main antioxidant compounds}

Mean values of bioactive compounds and of antioxidant activity in the fruits of control and mycorrhizal plants are given in Table 3. Comparing the composition of tomatoes on a fresh matter basis is essential when the nutritional value of the fruit is considered. On a fresh matter basis, the concentrations of the bioactive compounds assayed, except lycopene, were similar in both treatments. Lycopene content of tomato fruits from mycorrhizal plants was $18.5 \%$ higher than that of controls.

Table 2. Quality parameters in control and mycorrhizal tomato fruits (Mean values with their standard errors of three replicates)

\begin{tabular}{lccccc}
\hline & \multicolumn{2}{c}{ Control } & & \multicolumn{2}{c}{ Mycorrhizal } \\
\cline { 2 - 3 } & Mean & SE & & Mean & SE \\
\hline DM (\%) & 5.77 & 0.03 & & 5.74 & 0.09 \\
pH & 4.07 & 0.01 & & 4.05 & 0.04 \\
Soluble solids ( ${ }^{\circ}$ Brix) & 4.29 & 0.22 & & 4.04 & 0.47 \\
Acidity (g citric acid/100 g) & 0.32 & 0.01 & & 0.32 & 0.01 \\
\hline
\end{tabular}

Mean values were not significantly different between control and mycorrhizal values $(P>0.05$; two-tailed paired $t$ test). 
Table 3. Bioactive compounds in control and mycorrhizal tomato fruits (Mean values with their standard errors of three replicates)

\begin{tabular}{|c|c|c|c|c|}
\hline \multirow[b]{2}{*}{ Compounds } & \multicolumn{2}{|c|}{$\begin{array}{c}\text { Control } \\
(\mathrm{mg} / \mathrm{kg} \mathrm{FW})\end{array}$} & \multicolumn{2}{|c|}{$\begin{array}{l}\text { Mycorrhizal } \\
\text { (mg/kg FW) }\end{array}$} \\
\hline & Mean & SE & Mean & SE \\
\hline Lycopene & $53 \cdot 2$ & $2 \cdot 24$ & $63.06^{*}$ & 1.71 \\
\hline Reduced ascorbate & $175 \cdot 2$ & $16 \cdot 66$ & 149.50 & 4.77 \\
\hline Oxidised ascorbate & $20 \cdot 65$ & $1 \cdot 13$ & 27.43 & $16 \cdot 5$ \\
\hline Reduced glutathione & $33 \cdot 61$ & $2 \cdot 58$ & 33.49 & 0.84 \\
\hline Oxidised glutathione & $13 \cdot 38$ & 0.38 & 13.42 & 0.26 \\
\hline Total phenols $\dagger$ & $58 \cdot 21$ & $1 \cdot 31$ & $56 \cdot 82$ & 1.05 \\
\hline
\end{tabular}

FW, fresh weight.

* Mean values were significantly different between control and mycorrhizal values ( $P \leq 0.01$; two-tailed paired $t$ test).

$\dagger \mathrm{mg}$ quercetin/kg FW.

The redox state of ascorbate expressed as the ratio of ASC to total ascorbate ranged from 0.85 to 1.0 in fruits from both treatments. The glutathione ratio (GSH:GSH + GSSG) was roughly 0.7 in fruits both of control and mycorrhizal tomato plants.

In the present study, the $\mathrm{ABTS}^{+}{ }^{+}$radical cation assay was performed to test antioxidant activity. This assay is widely used because it is easy to perform and helpful in analysing both hydrophilic and lipophilic compounds. Antioxidant activity values of water-soluble and water-insoluble fractions showed no significant differences between treatments.

\section{In vitro mutagenicity assays}

The presence of mutagenic compounds in raw plant extracts was assessed by the in vitro Ames test and the MN assay in human lymphocytes for evaluation of gene and chromosome mutation, respectively. In no case did HE or LE (from fruits of mycorrhizal and non-mycorrhizal tomato plants) increase the spontaneous reversion frequency of Salmonella strains with and without metabolic activation (data not shown). Table 4 lists the results of the MN test. Treatment of cultures with HE from fruits of mycorrhizal and control plants induced no significant variation in the baseline levels of $\mathrm{MN}$ or in cell proliferation up to the maximum concentration tested $(10 \mathrm{mg} / \mathrm{ml})$. Similar results were observed when lymphocytes were treated with LE of tomato fruits from mycorrhizal and non-mycorrhizal plants, although a slight, but non-significant, increase in cytotoxicity was observed at $1.5 \mathrm{mg} / \mathrm{ml}$. As expected, the reference mutagen bleomycin induced highly significant $(P<0.001)$ increases $(18.00$ (SE 8.48) and 68.50 (sE 19.50$) \%$ ) in the spontaneous $\mathrm{MN}$ frequencies $(0.50$ (SE 0.50$)$ and $11.50(\mathrm{SE} 3.50) \%$ ) and a substantial reduction in cell division.

\section{Oestrogenic/anti-oestrogenic activity}

LE exhibited weak oestrogenic activity in YES, depending on the concentration tested. At $0 \cdot 1 \mathrm{mg} / \mathrm{ml}$, this extract produced $26.6 \% \quad \beta$-galactosidase activity. A significant difference $(P<0.0001)$ between extracts of fruits produced by mycorrhizal and control plants was observed. The antagonistic action of tomato extracts is shown in Fig. 1. Both LE (Fig. 1(a)) and HE (Fig. 1(b)) exerted a significant $(P<0 \cdot 0001)$ dose-dependent inhibition of $E_{2}$ activity. The activity expressed by LE was characterised by an exponential dose-response relationship and, overall, it was higher than the activity induced by HE $(P<0.05)$. In particular, at the highest concentration tested, LE of tomato fruits produced by mycorrhizal plants exhibited a $93.3 \%$ inhibition of the activity induced by $1 \mathrm{~nm}-\mathrm{E}_{2}$, while

Table 4. Micronucleus (MN) assay in human lymphocytes treated by hydrophilic and lipophilic extracts of tomato fruits obtained from control and mycorrhizal plants

(Mean values with their standard errors of two independent experiments)

\begin{tabular}{|c|c|c|c|c|c|c|c|c|}
\hline \multirow[b]{2}{*}{ Extract concentration $(\mathrm{mg} / \mathrm{ml})$} & \multicolumn{4}{|c|}{ Control } & \multicolumn{4}{|c|}{ Mycorrhizal } \\
\hline & MN frequency (\%o) & $\mathrm{SE}$ & $\mathrm{CPI}$ & SE & MN frequency (\%o) & SE & $\mathrm{CPI}$ & SE \\
\hline \multicolumn{9}{|l|}{ Hydrophilic } \\
\hline $0\left(\mathrm{H}_{2} \mathrm{O}\right)$ & 0.50 & 0.50 & 1.86 & 0.02 & & & & \\
\hline 0.016 & 0.50 & 0.50 & $1 \cdot 88$ & 0.04 & 1.00 & 1.00 & 1.89 & 0.07 \\
\hline 0.08 & 0.50 & 0.50 & 1.90 & 0.08 & 0.50 & 0.50 & 1.85 & 0.08 \\
\hline 0.4 & 1.50 & 0.50 & 1.96 & 0.01 & 1.00 & 0.00 & 1.91 & 0.02 \\
\hline 2 & 1.00 & 0.00 & 1.92 & 0.01 & 1.00 & 1.00 & 1.91 & $0 \cdot 10$ \\
\hline 10 & 1.50 & 0.50 & 1.93 & 0.05 & $2 \cdot 33$ & $1 \cdot 20$ & 1.89 & 0.08 \\
\hline \multicolumn{9}{|l|}{ Bleomycin } \\
\hline $2.5 \mu \mathrm{g} / \mathrm{ml}$ & $18 \cdot 00^{\star \star \star}$ & $8 \cdot 48$ & $1.48^{\star \star}$ & 0.01 & & & & \\
\hline \multicolumn{9}{|l|}{ Lipophilic } \\
\hline 0 (1\% DMSO) & 11.50 & 3.50 & 1.94 & 0.09 & & & & \\
\hline 0.0024 & $9 \cdot 50$ & 2.50 & 1.84 & 0.07 & 11.00 & $2 \cdot 00$ & 1.81 & 0.06 \\
\hline 0.012 & $10 \cdot 50$ & 4.50 & $1 \cdot 76$ & 0.13 & $13 \cdot 50$ & 0.50 & $1 \cdot 89$ & 0.08 \\
\hline 0.06 & $15 \cdot 00$ & 2.00 & 1.67 & 0.05 & 11.50 & 4.50 & 1.95 & 0.08 \\
\hline 0.3 & 11.50 & 2.50 & 1.68 & 0.05 & 11.00 & 4.00 & $2 \cdot 02$ & 0.01 \\
\hline 1.5 & 12.50 & 0.50 & $1 \cdot 86$ & 0.09 & 12.50 & $2 \cdot 50$ & 1.59 & 0.04 \\
\hline \multicolumn{9}{|l|}{ Bleomycin } \\
\hline $2.5 \mu \mathrm{g} / \mathrm{ml}$ & $68 \cdot 50^{\star \star \star}$ & 19.50 & $1 \cdot 21^{\star \star}$ & 0.01 & & & & \\
\hline
\end{tabular}

CPI, cell proliferation index; DMSO, dimethyl sulfoxide.

Mean values were significantly different from the control $(0 \mathrm{mg} / \mathrm{ml})$ : ${ }^{\star \star} P<0.01,{ }^{\star \star \star} P<0.001$. 



Hydrophilic extract concentration $(\mathrm{mg} / \mathrm{ml})$

Fig. 1. Anti-oestrogenic effect induced by (a) the lipophilic and (b) hydrophilic extracts of control ( $\square$ ) and mycorrhizal (ם) tomato fruits. To test for anti-oestrogenic activity, the yeast strain was incubated with 17- $\beta$-oestradiol $\left(E_{2}\right)$ in the presence or absence of samples. Activity of the extracts is expressed as inhibition (\%) of the activity induced by $1 \mathrm{~nm}-\mathrm{E}_{2}(100 \%)$. Values are means of three independent experiments, with standard deviations represented by vertical bars. $\beta$-gal, $\beta$-Galactosidase.

$\mathrm{HE}$ of the same tomatoes showed a $70 \cdot 7 \%$ decrease in $\mathrm{E}_{2}$ activity. For both LE and HE, the inhibitory action was significantly affected by the mycorrhizal treatment $(P<0.0001)$. Moreover, HE of fruits from both mycorrhizal and control plants affected yeast cell proliferation (185.5 and $173.5 \%$, respectively).

In the concentration range tested, lycopene was not oestrogenic, but showed a dose-dependent inhibition of $\mathrm{E}_{2}$ activity (20-50\% inhibition, depending on the dose).

\section{Discussion}

To the best of our knowledge, this is the first multidisciplinary study on the nutraceutical value and safety of mycorrhizal tomato fruits. The present data show that inoculation with G. intraradices positively affected the growth and mineral nutrient content of tomato plants, and enhanced the nutritional and nutraceutical value of tomato fruits through modifications of plant secondary metabolism, without production of mutagenic compounds. Moreover, fruits produced by mycorrhizal tomato plants showed significantly higher anti-oestrogenic activity.

Mycorrhizal colonisation by $G$. intraradices exerted a positive effect on plant growth and nutrition, with enhanced uptake of soil mineral nutrients, in particular P, K, Ca and $\mathrm{Zn}$. This is not unexpected, since a considerable body of evidence has shown improved nutritional status of mycorrhizal plants compared with controls ${ }^{(9)}$. Tomato is not considered a highly mycotrophic plant and both mycorrhizal establishment and host benefit may depend on host varieties ${ }^{(44)}$ and fungal species $^{(45)}$. 
AMF inoculation enhanced the nutritional status of tomatoes. $\mathrm{Ca}, \mathrm{K}, \mathrm{P}$ and $\mathrm{Zn}$ content of fruits of mycorrhizal plants was higher than in control plants. Interestingly, fruit $\mathrm{P}$ and $\mathrm{Zn}$ content of mycorrhizal plants was 60 and $28 \%$ higher than that of controls, respectively. Similar results were obtained in a field experiment using a mycorrhizal defective tomato mutant $(\mathrm{rmc})$ and its mycorrhizal wild type $\left(76 \mathrm{R}\right.$ MYC + plants) ${ }^{(46)}$. The present data show that AMF colonisation can improve the nutritional value of tomatoes, which is an important finding since $\mathrm{Zn}$ has been identified as a key human mineral nutrient ${ }^{(47)}$.

A particularly interesting result of the present study is the enhanced level of lycopene found in tomato fruits produced by mycorrhizal plants compared with controls, while the levels of other bioactive compounds were similar to control values.

In this context, we demonstrated that extracts of tomato fruits produced by mycorrhizal plants induced no in vitro genotoxic effect. In the present study, two tests were used for genotoxicity assessment: the Ames Salmonella/microsome mutagenicity assay ${ }^{(48)}$, which represents the 'first line' for detection of gene mutation, and the human lymphocyte MN test $^{(49)}$, a 'first line' test for detecting chromosome aberrations. In the present findings, we detected no mutagenic polyphenol with DNA-damaging activity ${ }^{(5,7)}$. Although several studies have shown the chemoprotective/chemopreventive effects of phytochemicals ${ }^{(38,50-52)}$, other investigations have reported that plant extracts can be genotoxic due to the presence of high concentrations of particular secondary metabolites ${ }^{(53,54)}$. On the basis of the present results, and since lycopene has been found to possess anti-genotoxic/anti-carcinogenic properties $^{(55,56)}$, we hypothesised that the higher lycopene content detected in mycorrhizal tomato plants succeeded in neutralising the DNA-damaging activity of any possible mutagenic compound occurring in tomato fruits.

Tomato extracts from control and mycorrhizal plants exhibited weak oestrogenic action, as maximum $\beta$-galactosidase activity, observed for LE, was $26.6 \%$. The present results indicated that tomato extracts, above all the lipophilic fraction, strongly inhibited $\mathrm{E}_{2}$-human oestrogen receptor binding and that mycorrhizal inoculation significantly increased the anti-oestrogenic power of tomato fruits. The higher inhibitory effect induced by LE could bear a relationship to the distribution of compounds capable of binding oestrogen receptor, such as flavonoids and lycopene, in tomato fruits. More specifically, the major flavonoids of tomato, naringenincalchone and rutin ${ }^{(57)}$, are mainly contained (98\%) in $\mathrm{LE}^{(58)}$, as well as other compounds of a lipophilic nature (e.g. carotenoids). The inhibitory effect observed for lycopene in the YES test is in agreement with data concerning the $\mathrm{E}_{2}$-antagonistic effect of this compound on different in vitro systems ${ }^{(59,60)}$.

Recently, polyphenols and lycopene have been proposed as promising pharmacological agents in cancer prevention on account of their antiproliferative effects and their inhibitory action on the human oestrogen receptors ${ }^{(61-63)}$. In particular, anti-oestrogenic compounds can antagonise oestrogen-dependent processes in their target tissues, counteracting the growth of oestrogen-related cancers. The present results suggest that intake of functional foods such as tomato fruits produced by mycorrhizal plants could antagonise in vivo the oestrogen-like activity known to be elicited by several environmental-industrial xenobiotics to which humans are exposed through the food chain ${ }^{(64,65)}$.

In conclusion, AMF are ecologically and economically important micro-organisms playing a major role in sustainable food production systems, by reducing the input of chemical fertilisers and pesticides ${ }^{(66)}$. Thus, they not only ensure lesser environmental damage but also allow safe production of high-quality food, which is an important societal issue, strongly in accordance with the demand expressed both by consumers and producers.

\section{Acknowledgements}

The present study was supported by the University of Pisa (Progetti di Ateneo 2006), by Cassa di Risparmio di Lucca Pisa e Livorno and by CNR. The authors declare no conflicts of interest. M. G., R. B. and D. R conceived and designed the experiments. L. A., N. C., R. C., A. I., F. M., P. P., B. P., C. S. and R. S. performed the experiments and analysed the data. M. G., R. B. and D. R. contributed reagents/materials/ analysis tools. M. G., N. C., P. P., B. P., D. R., C. S. and R. S. wrote the manuscript.

\section{References}

1. Williams C (1995) Healthy eating: clarifying advice about fruit and vegetables. BMJ 310, 1453-1455.

2. Balsano C \& Alisi A (2003) Antioxidant effects of natural bioactive compounds. Curr Pharm Des 15, 3063-3073.

3. Pal S, Khossousi A, Binns C, et al. (2011) The effect of a fibre supplement compared to a healthy diet on body composition, lipids, glucose, insulin and other metabolic syndrome risk factors in overweight and obese individuals. Br J Nutr 105, 90-100.

4. Duthie SJ (2000) Plant polyphenols in cancer and heart disease: implications as nutritional antioxidants. Nut Res Rev 13, 79-106.

5. Brusick D (1993) Genotoxicity of phenolic antioxidants. Toxicol Ind Health 9, 223-230.

6. Duthie SJ (2003) The comet assay: protective effects of dietary antioxidants against oxidative DNA damage measure using alkaline single cell gel electrophoresis. In Critical Reviews of Oxidative Stress and Aging, vol. 1, pp. 309-323 [RJ Cutler and $\mathrm{H}$ Rodriguez, editors]. River Edge, NJ: World Scientific.

7. Stopper H, Schmitt E \& Kobras K (2005) Genotoxicity of phytoestrogens. Mutat Res 574, 139-155.

8. Wink M (1988) Plant breeding: importance of plant secondary metabolites for protection against pathogens and herbivores. Theor Appl Genet 75, 225-233.

9. Smith SE \& Read DJ (2008) Mycorrhizal Symbiosis. Cambridge: Academic Press.

10. Peipp H, Maier W, Schmidt J, et al. (1997) Arbuscular mycorrhizal fungus-induced changes in the accumulation of secondary compounds in barley roots. Phytochemistry 44, 581-587.

11. Alguacil MM, Hernández JA, Caravaca F, et al. (2003) Antioxidant enzyme activities in shoots from three mycorrhizal 
shrub species afforested in a degraded semi-arid soil Plant Physiol 118, 562-570.

12. Lambais MR, Rios-Ruiz WF \& Andrade RM (2003) Antioxidant responses in bean (Phaseolus vulgaris) roots colonized by arbuscular mycorrhizal fungi. New Phytol 160, 421-428.

13. Walter MH, Fester T \& Strack D (2000) Arbuscular mycorrhizal fungi induce the non-mevalonate methylerythriol phosphate pathway of isoprenoid biosynthesis correlated with accumulation of the "yellow pigment" and other apocarotenoids. Plant J 21, 571-578.

14. Fester T, Schmidt D, Lohse S, et al. (2002) Stimulation of carotenoid metabolism in arbuscular mycorrhizal roots. Planta 216, 148-154.

15. Ceccarelli N, Curadi M, Martelloni L, et al. (2010) Mycorrhizal colonization impacts on phenolic content and antioxidant properties of artichoke leaves and flower heads two years after field transplant. Plant Soil 335, 311-323.

16. Subramanian KS, Santhanakrishnan P \& Balasubramanian P (2006) Responses of field grown tomato plants to arbuscular mycorrhizal fungal colonization under varying intensities of drought stress. Sci Hort 107, 245-253.

17. Dornstauder E, Jisa E, Unterrieder I, et al. (2001) Estrogenic activity of two standardized red clover extracts (Menoflavon) intended for large scale use in hormone replacement therapy. J Steroid Biochem Mol Biol 78, 67-75.

18. Ososki AL \& Kennelly EJ (2003) Phytoestrogens: a review of the present state of research. Phytother Res 17, 845-869.

19. Marinangeli CPF \& Jones PJH (2011) Whole and fractionated yellow pea flours reduce fasting insulin and insulin resistance in hypercholesterolaemic and overweight human subjects. Br J Nutr 105, 110-117.

20. Moutsatsou P (2007) The spectrum of phytoestrogens in nature: our knowledge is expanding. Hormones (Athens) 6, 173-193.

21. Khaosaad T, Krenn L, Medjakovic S, et al. (2008) Effect of mycorrhization on the isoflavone content and the phytoestrogen activity of red clover.JPlant Physiol 165, 1161-1167.

22. Willcox JK, Catignani GL \& Lazarus S (2003) Tomatoes and cardiovascular health. Crit Rev Food Sci 43, 1-18.

23. Canene-Adams K, Campbell JK, Zaripheh S, et al. (2005) The tomato as a functional food. J Nutr 135, 1226-1230.

24. Silaste M-L, Alfthan G, Aro A, et al. (2007) Tomato juice decreases LDL cholesterol levels and increases LDL resistance to oxidation. Brit J Nutr 98, 1251-1258.

25. Palozza P, Bellovino D, Simone R, et al. (2009) Effect of $\beta$-carotene-rich tomato lycopene $\beta$-cyclase (tlcy-b) on cell growth inhibition in HT-29 colon adenocarcinoma cells. Br J Nutr 102, 207-214

26. Raffo A, Leonardi C, Fogliano V, et al. (2002) Nutritional value of cherry tomatoes (Lycopersicon esculentum cv. Naomi F1) harvested at different ripening stages. J Agric Food Chem 50, 6550-6556.

27. Di Mascio P, Kaiser S \& Sies H (1989) Lycopene as the most efficient biological carotenoid singlet oxygen quencher. Arch Biochem Biophys 274, 532-538.

28. Rao AV \& Agarwal S (1999) Role of lycopene as antioxidant carotenoid in the prevention of chronic diseases: a review. Nutr Res 19, 305-323.

29. Phillips JM \& Hayman DS (1970) Improved procedures for clearing roots and staining parasitic and vesiculararbuscular mycorrhizal fungi for rapid assessment of infection. Trans Br Mycol Soc 55, 158-160.

30. Giovannetti M \& Mosse B (1980) An evaluation of techniques for measuring vesicular-arbuscular mycorrhizal infection in roots. New Phytol 84, 489-500.
31. Fish WW, Perkins-Veaziea P \& Collins JK (2002) Quantitative assay for lycopene that utilizes reduced volumes of organic solvents. J Food Comp Anal 15, 309-317.

32. Gillespie KM \& Ainsworth EA (2007) Measurement of reduced, oxidized and total ascorbate content in plants. Nat Protoc 2, 871-874.

33. Anderson ME (1985) Determination of glutathione and glutathione disulfide in biological samples. Methods Enzymol 113, 548-555.

34. Ainsworth EA \& Gillespie KM (2007) Estimation of total phenolic content and other oxidation substrates in plant tissues using Folin-Ciocalteu reagent. Nature Protocols 2, 875-877.

35. Cano A, Acosta M \& Arnao MB (2003) Hydrophilic and lipophilic antioxidant activity changes during on-vine ripening of tomatoes (Lycopersicon esculentum Mill.). Postharvest Biol Technol 28, 59-65.

36. Maron DM \& Ames BN (1983) Revised methods for the Salmonella mutagenicity test. Mutat Res 113, 173-215.

37. Fenech M (2005) In vitro micronucleus technique to predict chemosensitivity. Methods Mol Med 111, 3-32.

38. Scarpato R, Paganucci L, Bertoli A, et al. (2008) Licoflavone C attenuates the genotoxicity of cancer drugs in human peripheral lymphocytes. Phytother Res 22, 1650-1654.

39. Liu JW, Jeannin E \& Picard D (1999) The anti-estrogen hydroxytamoxifen is a potent antagonist in a novel yeast system. Biol Chem 380, 1341-1345.

40. Pinto B, Picard D \& Reali D (2004) A recombinant yeast strain as a short term bioassay to assess estrogen-like activity of xenobiotics. Ann $\operatorname{Ig} \mathbf{1 6}, 579-585$.

41. Pinto B, Garritano S \& Reali D (2005) Occurrence of estrogenlike substances in the marine environment of the Northern Mediterranean Sea. Mar Pollut Bull 50, 1681-1685.

42. Beresford N, Routledge EJ, Harris CA, et al. (2000) Issues arising when interpreting results from an in vitro assay for estrogenic activity. Toxicol Appl Pharmacol 62, 22-33.

43. Ho LC (2003) Genetic and cultivation manipulation for improving tomato fruit quality. Acta Hort (ISHS) 613, 21-31.

44. Bryla DR \& Koide RT (1998) Mycorrhizal response of two tomato genotypes relates to their ability to acquire and utilize phosphorus. Ann Bot 82, 849-857.

45. Gao LL, Delp G \& Smith SE (2001) Colonisation patterns in a mycorrhiza-defective mutant tomato vary with different arbuscular-mycorrhizal fungi. New Phytol 151, 477-491.

46. Cavagnaro TR, Jackson LE, Six J, et al. (2006) Arbuscular mycorrhizas, microbial communities, nutrient availability, and soil aggregates in organic tomato production. Plant Soil 282, 209-225.

47. Welch RM \& Graham RD (2004) Breeding for micronutrients in staple food crops from a human nutrition perspective. J Exp Bot 55, 353-364.

48. Mortelmans K \& Zeiger E (2000) The Ames Salmonella/ microsome mutagenicity assay. Mutat Res 455, 29-60.

49. Fenech M (2006) Cytokinesis-block micronucleus assay evolves into a "cytome" assay of chromosomal instability, mitotic dysfunction and cell death. Mutat Res 600, 58-66.

50. Mersch-Sundermann V, Kassie F, Böhmer S, et al. (2004) Extract of Toxicodendron quercifolium caused genotoxicity and antigenotoxicity in bone marrow cells of CD1 mice. Food Chem Toxicol 42, 1611-1617.

51. Scarpato R, Bertoli A, Naccarati A, et al. (1998) Different effects of newly isolated saponins on the mutagenicity and cytotoxicity of the anticancer drugs mitomycin $\mathrm{C}$ and bleomycin in human lymphocytes. Mutat Res 420, 49-54.

52. Siddique YH \& Afzal M (2009) Antigenotoxic effect of apigenin against mitomycin $\mathrm{C}$ induced genotoxic damage in mice bone marrow cells. Food Chem Toxicol 47, 536-539. 
53. Rietjens MCMI, Boersma MG, van der Woude H, et al. (2005) Flavonoids and alkenylbenzenes: mechanisms of mutagenic action and carcinogenic risk. Mutat Res 574, 124-138.

54. Noel S, Kasinathan M \& Rath SK (2006) Evaluation of apigenin using in vitro cytochalasin blocked micronucleus assay. Toxicol In Vitro 20, 1168-1172.

55. Velmurugan B, Santhiya ST \& Nagini S (2004) Protective effect of S-allylcysteine and lycopene in combination against $N$-methyl- $N^{\prime}$-nitro- $N$-nitrosoguanidine-induced genotoxicity. Pol J Pharmacol 56, 241-245.

56. Scolastici C, Alves de Lima RO, Barbisan LF, et al. (2008) Antigenotoxicity and antimutagenicity of lycopene in HepG2 cell line evaluated by the comet assay and micronucleus test. Toxicol In Vitro 22, 510-514.

57. Slimestad R, Fossen T \& Verheul MJ (2008) The flavonoids of tomatoes. J Agric Food Chem 56, 2436-2441.

58. Lavelli V, Hippeli S, Dornisch K, et al. (2001) Properties of tomato powders as additives for food fortification and stabilization. J Agric Food Chem 49, 2037-2042.

59. Fornelli F, Leone A, Verdesca I, et al. (2007) The influence of lycopene on the proliferation of human breast cell line (MCF-7). Toxicol In Vitro 21, 217-223.

60. Hirsch K, Atzmon A, Danilenko M, et al. (2007) Lycopene and other carotenoids inhibit estrogenic activity of 17 beta-estradiol and genistein in cancer cells. Breast Cancer Res Treat 104, 221-230.

61. D'Incalci M, Steward WP \& Gescher AJ (2005) Use of cancer chemopreventive phytochemicals as antineoplastic agents. Lancet Oncol 6, 899-904.

62. Thomasset SC, Berry DP, Garcea G, et al. (2006) Dietary polyphenolic phytochemicals - promising cancer chemopreventive agents in humans? A review of their clinical properties. Int J Cancer 120, 451-458.

63. Pinto B, Bertoli A, Noccioli C, et al. (2008) Estradiol-antagonistic activity of phenolic compounds from leguminous plants. Phytother Res 22, 362-366.

64. Pinto B, Garritano S, Cristofani R, et al. (2008) Monitoring of polychlorinated biphenyl contamination and estrogenic activity in water, commercial feed and farmed seafood. Environ Monit Assess 144, 445-453.

65. Pinto B \& Reali D (2009) Screening of estrogen-like activity of mineral water stored in PET bottles. Int J Hyg Environ Medicine 212, 228-232.

66. Giovannetti M \& Avio L (2002) Biotechnology of arbuscular mycorrhizas. In Applied Mycology and Biotechnology, vol. 2, pp. 275-310 [GG Khachatourians and DK Arora, editors]. Amsterdam: Elsevier BV. 